\title{
System Dynamics Research on Economic Transformation and Environmentally Coordinated Development in China's Eastern Coastal Region
}

\author{
Tangjun Li, Ni Liu*, Qi Zhang \\ College of Economics and Management, Shandong University of Science and Technology, \\ Qingdao, Shandong Province, China
}

Received: 31 August 2018

Accepted: 18 October 2018

\begin{abstract}
The developed eastern coastal cities of China are leaders of the national economy, which is growing rapidly. However, with this growth has come substantial misuse of resources causing significant environmental damage, including some $85 \%$ of global greenhouse gases resulting from the impact of economic development. To explore a reasonable approach to coordinated development of economic growth and the environment, this paper assesses the city of Qingdao, employing regression analysis and other methods to establish an economic-energy-carbon emissions-social system dynamics model with a new industrial structure based on the degree of pollution. On the basis of new industrial structures, three separate schemes are formed by different combinations of sensitive variables. The research shows that over-emphasis on the environment or production of control measures are not appropriate under the current economic modality. Overemphasis on the environment will lead to rapid decline in economic growth and even the loss of economic growth momentum. Over-emphasis on production will result in a sharp increase in carbon emissions, accelerating the destruction of the environment and causing irreparable losses. Only by taking moderate measures on the basis of the current economic conditions can we achieve the desired economic and ecological goals.
\end{abstract}

Keywords: regional economy; new industrial structure; pollution; coordinated development

\section{Introduction}

With the rapid development of the Chinese economy, the pace of industrialization and urbanization are accelerating. Overall, $85 \%$ of global greenhouse gases come from economic development. Resource waste, environmental pollution and the global greenhouse

*e-mail: liuniyes@qq.com effect are becoming increasingly serious, making the coordinated development of the economy and environment a new global initiative. In response to this challenge, China, the world's second largest economy, has put forward a series of policies to transform approaches to economic development and improve the ecological environment. As the leader of the national economy, the developed eastern coastal areas urgently need to change their approaches to facilitating harmonious coordinated economic and environmental development. 
The city of Qingdao, for example, has continued to accelerate the transformation of economic development and promote economic growth. Since changing the original economic growth strategy, Qingdao has made achievements in economic growth, and improved living standards and the environment. Approaches to economic development have also changed, but at an insufficient level. Indeed, there are still many challenges stymying successful economic development [1].

At present, researchers tend to investigate coordinated economic transformation and environmental development from different perspectives. First, carbon emissions' influential role is one key research foci, and it is the basis for studying the coordinated economic transformation and environmental development. For example, Shyamal Paul and R.N. Bhattacharya [2], and G. ipek Tunc et al. [3] conducted rigorous research on the central factors of carbon emissions from an energy consumption perspective. Additionally, Zhu Q. et al. [4] and Pang J. et al. [5] explored the fundamental impact of carbon emissions from the consumers' perspective. Zhang J.H. et al. [6] and Zhou Y.X. et al. [7] examined the main factors of carbon emissions from the perspective of urban transport energy consumption. In summary, researchers believe that the main factors affecting carbon emissions are energy consumption, population size, economic level and urban transportation. Energy consumption, population size and urban transportation are closely related to the level of economic development. Therefore, the relationship between carbon emissions and economic growth has been assessed. Asafu-Adjaye J. and Mahadevan R. [8], Duro J.A. and Padilla E. [9], U. Bastola and P. Sapkota [10], and Fan T.S. [11] analyzed the relationship between carbon emissions and economic growth, finding that carbon emissions policies, economic development levels, industrial structure, and population size each play an important role in regulating the relationship. In particular, Jorgenson et al. [12] emphasized how economic growth is different in different industries or sectors, so accounting for economic growth by industry rather than using aggregate data to describe the full picture of economic growth. Therefore, adjusting the relationship between carbon emissions and economic growth by industrial structure and other key factors, and finding the appropriate development mode, has proven to be significant. Utilizing historical data, MINIHAN E.S. and W.U. Ziping [13], Xu T. [14], Yuan Y.J. and Xie R.H. [15] evaluated the impact of industrial restructuring on environmental pollution. In turn, PARK S. et al. [16], ASLANI A. et al. [17], Han N. [18], Xu S.H. and $\mathrm{Wu}$ D. [19] not only analyzed the impact of industrial restructuring, but also predicted the impact of industrial restructuring on future changes in environmental pollution, which provides a reference for government departments' energy policies.

The aforementioned research demonstrates that myriad scholars have attempted to better understand inharmonious economy and environmental development. However, through social development and various new industries, environmental pollution is becoming more diversified, and coordination between the economy and environment has been increasingly complicated. The methods that promote economic restructuring based on the restructuring of three industries, agriculture, industry and services, which are commonly used in the past research, fail to accurately distinguish the economic contribution, pollution intensity and pollution types from the three industries and cannot accurately address the new and complex environmental problems.

Given the gap in this research canon, this study proposes a new way of industrial division by reaffirming the division of industrial level based on pollution intensity, and analyzes the new industrial structure and evolution law, providing more accurate data analysis and support for the transformation of economic development modes. On the basis of the new industrial structure, this study employs the system dynamics method to simulate development in Qingdao using relevant historical data. Moreover, this study explores the law of different industry developments, and predicts economic and environmental development trends in Qingdao. The study adjusts sensitive variables to generate a scientific and rational development model meeting Qingdao's development goals. Our research findings will provide a reference for the transformation process from an extensive economy based on increased production factors to an intensive economy based on the optimization of production factors to improve the quality of production factors and efficiency. The findings will also have implications for China's other developed coastal areas.

To our knowledge, we are the first to propose the development of a system dynamics model based on the industrial structure of "degree of pollution," an endeavor aimed at analyzing the law of industries' development and exploring harmonious development of regional economies and the environment.

\section{Construction of an Industrial Structure Evolution System in Qingdao}

\section{Industrial Division and Industrial Structure}

The division of the three industries is based on the difference in processing objects in material production. The three industries reflect the development process in human economic activities, but, importantly, cannot reflect environmental pollution as a result of economic activities. In this paper, industry will be divided into the following: 1) heavy pollution, 2) moderate pollution, 3) light pollution, and 4) green, according to the production process of carbon emissions in various production fields $[15,16]$. Results are shown in Table 1. 
Table 1. Results of industrial division.

\begin{tabular}{|c|c|c|}
\hline Name & Industry classification & Industry \\
\hline HPI & Heavy pollution industry & Mining, Production and Supply of Electricity, Gas and Water \\
\hline MPI & Moderate pollution industry & Manufacturing \\
\hline LPI & Light pollution industry & Construction, Services \\
\hline GI & Green industry & Farming, Forestry, Animal Husbandry and Fishery \\
\hline
\end{tabular}

Based on industrial division, we collected and sorted the industrial structure of the four industries over the past 15 years (Fig. 1)

As demonstrated in Fig. 1, the proportion of green industry decreased and stabilized at around $4 \%$ after 2010 . The ratio of light pollution industry fluctuates at around 45\%, showing a smooth, upward trajectory from 2010 to 2015 before finally reaching $59 \%$ in 2015 . Over the past 15 years, the proportion of moderate pollution industry decreased at first, then increased, and finally decreased and stabilized at around $37 \%$ in the past three years. The fluctuation of the proportion of heavy pollution industry is similar to the fluctuation of the moderate pollution industry, stabilizing at around $1.2 \%$ in the past three years. In conclusion, the trend of industrial structure change in the light, moderate and heavy pollution industries is not obvious, demonstrating that the industrial structure adjustment policy is not sufficiently stable. Moreover, the data illustrate that the proportion of heavy and moderate pollution industries is slightly higher, which is prohibitive to the development of a green economy.

\section{Construction of Industrial Structure Evolution System in Qingdao}

The industrial structure evolution system in Qingdao (ISESQ) is a complex system consisting of subsystems in economics, energy consumption, carbon dioxide emissions, resource environment, and social development, as well as other subsystems. For analytic efficiency, we divided ISESQ into subsystems in economics, carbon emissions, energy consumption, and social development.

An economic subsystem is the driving force behind Qingdao's industrial structure evolution. The investment in fixed assets of various industries determines the output value of each industry and the growth rate of regional GDP, and the investment ratio determines the development potential of the industry. Therefore, variables classified into the economic subsystem are fixed asset investment, regional GDP, industrial output value, investment proportion, growth in investment proportion, fixed asset depreciation, and total fixed assets.

A carbon emissions subsystem is the basis of economic development, reflecting the impact of economic development on the environment. Moreover, a carbon emissions subsystem is an important index system of low-carbon industrial structures. Carbon emissions depend on energy consumption, including carbon emissions of production activities and daily residents' activities. Main variables included in the carbon emissions subsystem are as follows: total carbon dioxide emission, increase of emission, absorbed dose, carbon emissions coefficient, and per capita carbon emissions.

An energy consumption subsystem is a bridge connecting economic subsystems and carbon emissions

\section{Industrial structure}

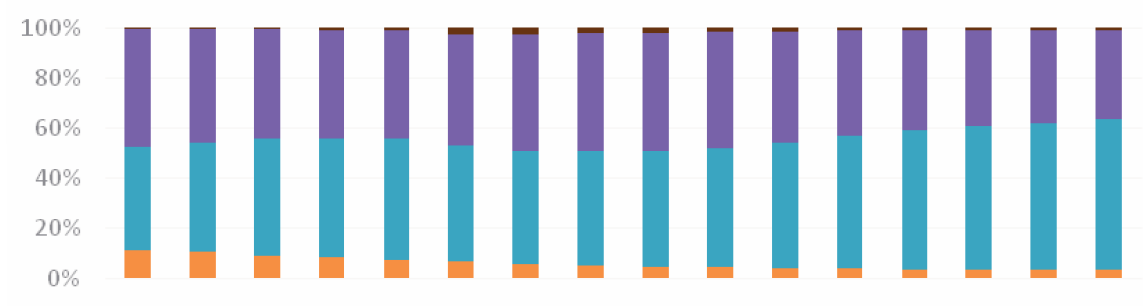

2000200120022003200420052006200720082009201020112012201320142015

$$
\begin{aligned}
& \text { - The output value of green industry } \\
& \text { - The output value of light pollution industry } \\
& \text { - The output value of moderate pollu tion industry } \\
& \text { - The output value of heavy pollution industry }
\end{aligned}
$$

Fig. 1. Industrial structures. 
subsystems. Economic development requires substantial energy. Some consumed energy will become carbon emitting into the environment, causing serious air pollution. Energy consumption subsystem variables include: energy consumption of various industries, consumption of productive energy, consumption of living energy, total amount of electricity, electricity output, electricity consumption, demand for external energy, and total energy consumption.

A social development subsystem is a system measuring the level of social development. The population is obviously social and represents the core element of the social development subsystem, and thus should be integrated into the social development subsystem. In addition, Qingdao has gradually attracted a large number of foreign individuals, which has had a notable influence on the population system. With the increasing development of society and the improvement of living standards, requirements for quality of life have substantially increased; this occurrence being accompanied by rising living energy consumption, which has an influence on the regional environment. Variables included in the social development subsystem include: household population, birth rate, mortality rate, migrant population, increment of migrant population, decrement of migrant population, total population, per capita GDP, green area, increment of green area, decrement of green area, per capita green space, increment of construction land, proportion of occupied agricultural land, increment of occupied agricultural land, increment of agricultural land, policy factors, total water volume, and decrement of water volume.

\section{Causal Loop Diagram and SD System of Industrial Structure}

The system dynamics model primarily describes the complex relationship within the system based on the causal loop diagram and the SD flow graph.

\section{Causal Loop Diagram}

Using the factors of economy, energy consumption, carbon dioxide emissions, and social development, we constructed a causal loop diagram of industrial structure evolution in Qingdao.

As shown in Fig. 2, the model consists of a number of causal loops; the main feedback loops are as follows:

Loop 1: $\mathrm{GDP} \rightarrow(+)$ investment in fixed assets $\rightarrow(+)$ the output value of each industry $\rightarrow(+)$ GDP

Loop 2: Environmental protection investment $\rightarrow(+)$ green investment $\rightarrow(+)$ green area $\rightarrow(+)$ carbon dioxide control $\rightarrow(-)$ carbon emissions $\rightarrow(-)$ environmental quality $\rightarrow(-)$ environmental protection investment

Loop 3: Living energy consumption $\rightarrow(+)$ carbon emissions $\rightarrow(-)$ policy constraints $\rightarrow(+)$ concept of low carbon consumption $\rightarrow(+)$ living energy consumption

Loop 4: Energy production $\rightarrow(-)$ lack of energy $\rightarrow(+)$ introduction of external energy $\rightarrow(-)$ productive energy consumption $\rightarrow(+)$ resource constraints $\rightarrow(-)$ energy production

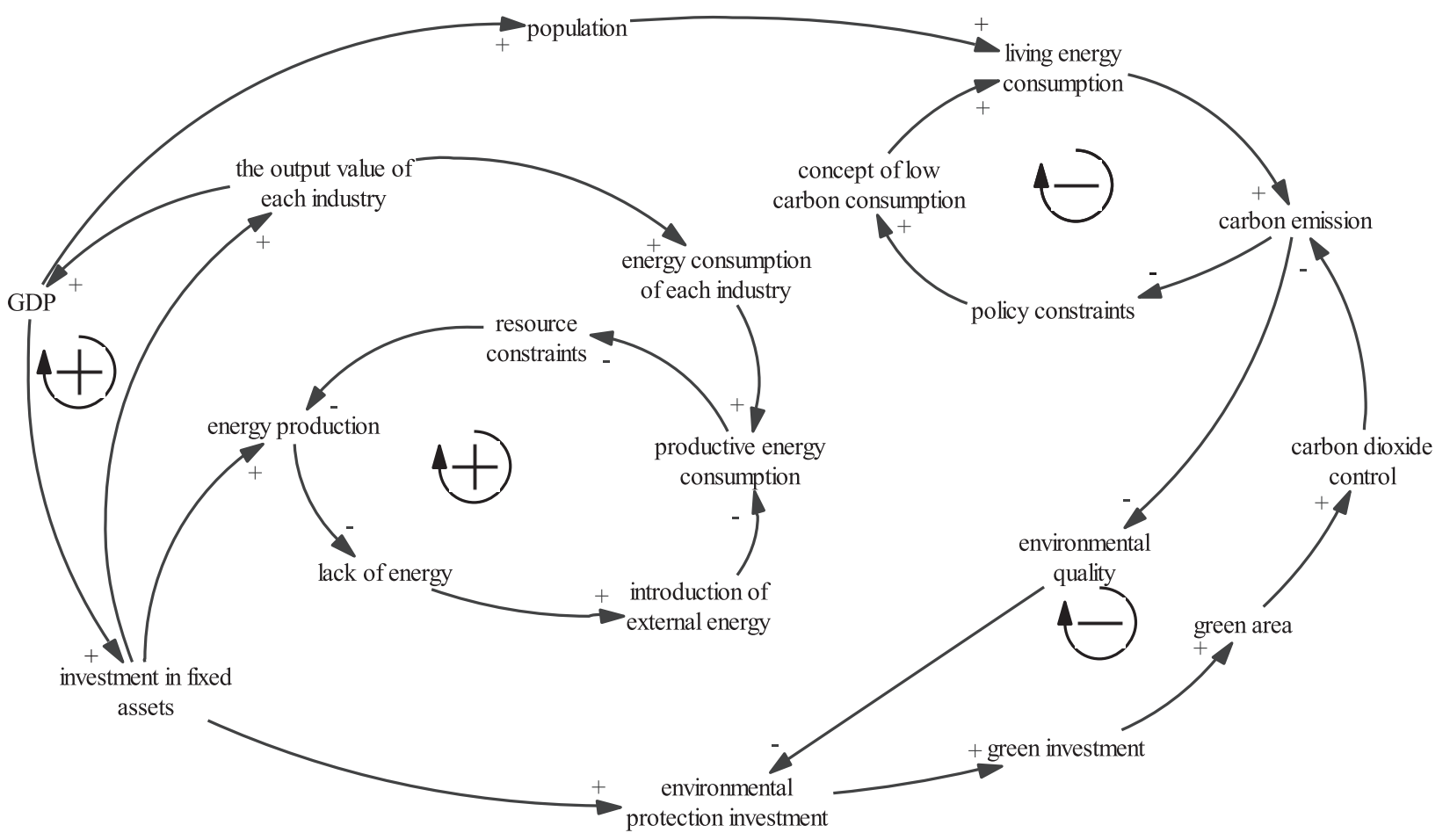

Fig. 2. Causal loop diagram. 


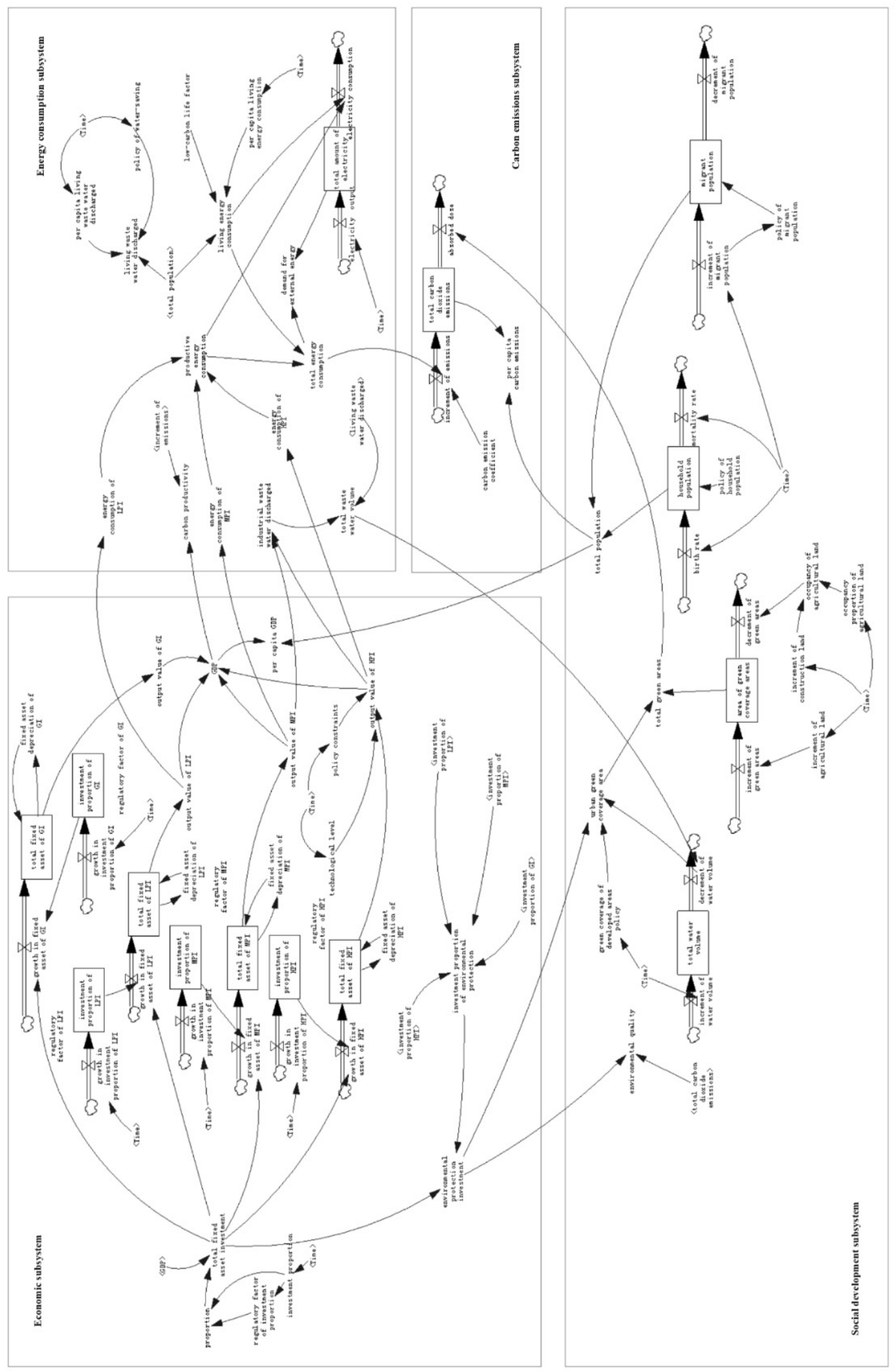

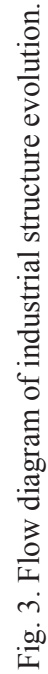


Table 2. Regression analysis on the output value and the total fixed assets of GI.

\begin{tabular}{|c|c|c|c|c|c|c|c|}
\hline \multirow{2}{*}{ Equation } & \multicolumn{9}{|c|}{ Dependent Variable: the output value of GI } & \multicolumn{3}{c|}{ Parameter Estimates } \\
\cline { 2 - 9 } & R Square & F & df1 & df2 & Sig. & Constant & b1 \\
\hline Inverse & .919 & 158.841 & 1 & 14 & .000 & 632.232 & -156858.572 \\
\hline
\end{tabular}

The independent variable is the total fixed assets of GI.

\section{Flow Diagram}

The causal loop diagram reflects the relationship among the variables, but establishing this relationship requires analysis of the accumulation, that is, stocks and flows. The SD flow diagram is shown in Fig. 3.

As shown in Fig. 3, the system consists of 14 state variables and 20 rate variables. All data are from the Qingdao Statistical Yearbook, Shandong Statistical Yearbook, China Energy Statistical Yearbook, the State Council Research Center Information Network, and other authoritative databases.

In consideration of related theories of production function and energy consumption, the relationship among variables is most optimally studied by regression analysis and a co-integration test. The main system dynamics equations are as follows:

(1) The output value and total fixed assets of GI

We hypothesized that there was a relationship between the output value and the total fixed assets of GI. Therefore, we conducted further analysis using regression analysis. Results are outlined in Table 2.

After the relevant test, the relationship between the output value and the total fixed assets of GI is:

\section{The output value of $G I=632.232-156859$ / \\ / The total fixed assets of GI}

(2) The output value and the total fixed assets of LPI

We hypothesized that there was a relationship between the output value and the total fixed assets of

Table 3. Regression analysis on the output value and the total fixed assets of LPI.

\begin{tabular}{|c|c|c|c|}
\hline R & R Square & $\begin{array}{c}\text { Adjusted } \\
\text { R Square }\end{array}$ & $\begin{array}{c}\text { Std. Error } \\
\text { of the Estimate }\end{array}$ \\
\hline .990 & .980 & .979 & .115 \\
\hline
\end{tabular}

The independent variable is the total fixed assets of LPI.

Table 4. Regression analysis on the output value and the total fixed assets of MPI.

\begin{tabular}{|c|c|c|c|}
\hline R & R Square & $\begin{array}{c}\text { Adjusted } \\
\text { R Square }\end{array}$ & $\begin{array}{c}\text { Std. Error } \\
\text { of the Estimate }\end{array}$ \\
\hline .993 & .987 & .986 & 121.969 \\
\hline
\end{tabular}

LPI. Therefore, we conducted further analysis using regression analysis. Results are shown in Table 3.

After the relevant test, the relationship between the output value and the total fixed assets of LPI is:

The output value of $L P I=0.872 \times \exp$

$(0.918 \times \ln ($ The total fixed assets of LPI $))$

(3) The output value and total fixed assets of MPI

We hypothesized that there was a relationship between the output value and the total fixed assets of MPI. Therefore, we conducted further analysis using regression analysis. The results are presented in Table 4.

After the relevant test, the relationship between the output value and the total fixed assets of MPI is:

The output value of MPI $=-11222.3+1556.42 \times \ln$

(The total fixed assets of MPI)

(4) The output value and the total fixed assets of HPI

We hypothesized that there was a relationship between the output value, total fixed assets of HPI, policy constraints, and technological level. Therefore, we conducted further analysis using regression analysis. Results are presented in Table 5.

After regression analysis, the relationship between output value and total fixed assets of HPI was:

Theoutput value of HPI $=-75.826+0.177 \times$ Thetotal fixed assets of $H P I+18.352 \times$ Policy constraints +22.083 $\times$ Technological level

(5) The output value and energy consumption of LPI

We hypothesized that there was a relationship between the output value and energy consumption of

Table 5. Regression analysis on the output value and the total fixed assets of HPI.

\begin{tabular}{|c|c|}
\hline Adjusted R Square & Std. Error of the Estimate \\
\hline .953 & 7.83423 \\
\hline
\end{tabular}

a. Predictors: (Constant), Technological level, The total fixed assets of HPI, Policy constraints 
Table 6. Regression analysis of the output value and energy consumption of LPI.

\begin{tabular}{|c|c|c|c|c|c|c|c|}
\hline \multicolumn{8}{|c|}{ Dependent Variable: the energy consumption of LPI } \\
\hline \multirow{2}{*}{ Equation } & \multicolumn{5}{|c|}{ Model Summary } & \multicolumn{2}{|c|}{ Parameter Estimates } \\
\hline & R Square & $\mathrm{F}$ & df1 & $\mathrm{df} 2$ & Sig. & Constant & b1 \\
\hline Power & .977 & 377.945 & 1 & 9 & .000 & 2836.016 & .673 \\
\hline
\end{tabular}

The independent variable is the output value of LPI.

Table 7. Regression analysis of the output value and energy consumption of MPI.

\begin{tabular}{|c|c|c|c|c|c|c|c|}
\hline \multicolumn{8}{|c|}{ Dependent Variable: the energy consumption of MPI } \\
\hline \multirow{2}{*}{ Equation } & \multicolumn{5}{|c|}{ Model Summary } & \multicolumn{2}{|c|}{ Parameter Estimates } \\
\hline & R Square & $\mathrm{F}$ & df1 & $\mathrm{df} 2$ & Sig. & Constant & b1 \\
\hline Power & .937 & 208.511 & 1 & 14 & .000 & 85286.933 & .739 \\
\hline
\end{tabular}

The independent variable is the output value of MPI.

LPI. Therefore, we conducted further analysis using regression analysis. Results are outlined in Table 6.

After the relevant test, the relationship between output value and energy consumption of LPI is:

\section{The energy consumption of $L P I=0.284 \times \exp$ $(0.673 \times \ln ($ The output value of $L P I))$}

(6) The output value and energy consumption of MPI

We hypothesized that there is a relationship between the output value and energy consumption of MPI. Therefore, we conducted further analysis using regression analysis. Results are shown in Table 7.

After the relevant test, the relationship between the output value and energy consumption of MPI was:

\section{The energy consumption of $M P I=85286.9 \times \exp$ $(0.739 \times \ln ($ The output value of $M P I))$}

(7) The output value and energy consumption of HPI

We hypothesized that there is a relationship between the output value and energy consumption of HPI. Therefore, we conducted further analysis using regression analysis. Results are shown in Table 8.

After the relevant test, the relationship between the output value and energy consumption of MPI was:

Table 8 . Regression analysis on the output value and energy consumption of HPI.

\begin{tabular}{|c|c|c|c|}
\hline R & R Square & $\begin{array}{c}\text { Adjusted } \\
\text { R Square }\end{array}$ & $\begin{array}{c}\text { Std. Error } \\
\text { of the Estimate }\end{array}$ \\
\hline .959 & .919 & .914 & .094 \\
\hline
\end{tabular}

The energy consumption of HPI $=2.15618 e+006$

$$
\times \exp (0.308 \times \ln (\text { The output value of HPI }))
$$

\section{Results and Discussion}

\section{Model Test}

A model test is a method to check for consistency between the operating system and the actual system, facilitating appropriate adjustments and corrections to the deviation to ensure model effectiveness. Simulation results of the main development indicators are obtained through the initial operation of the 2011-2015 Qingdao industrial structure system.

In this paper, the validity and reliability of the model are judged by the fitting degree of the system operation results and historical data from Qingdao. The error is calculated as follows:

$$
\mu=\left|\frac{\alpha^{\prime}-\alpha}{\alpha}\right|
$$

The error value of each indicator is calculated by Eq. (1), where $\mu$ is the error value, $\alpha^{\prime}$ is the analog value, and $\alpha$ is the actual value. We chose the representative indicators which could reflect the development of a lowcarbon economy in Qingdao. The simulation results are shown in Table 2.

As shown in Table 9, the overall error distribution interval is $[0,0.15]$, and the overall error is within $15 \%$, which is acceptable in system dynamics. It can be seen that the model has a high fitting degree and is capable of accurately describing the future development of the system. 
Table 9. Comparison of the main indicators of the analog and actual value.

\begin{tabular}{|c|c|c|c|c|c|c|}
\hline & & 2011 & 2012 & 2013 & 2014 & 2015 \\
\hline \multirow{3}{*}{ GDP } & The actual value & 6615.260 & 7302.110 & 8006.600 & 8699.250 & 9308.040 \\
\hline & The analog value & 6628.540 & 6573.320 & 7752.080 & 8141.630 & 8983.780 \\
\hline & The error & $0 \%$ & $10 \%$ & $3 \%$ & $6 \%$ & $3 \%$ \\
\hline \multirow{3}{*}{ The output value of GI } & The actual value & 306.380 & 324.410 & 352.410 & 349.620 & 363.980 \\
\hline & The analog value & 314.229 & 310.734 & 336.186 & 345.238 & 363.059 \\
\hline & The error & $3 \%$ & $4 \%$ & $5 \%$ & $1 \%$ & $0 \%$ \\
\hline \multirow{3}{*}{ The output value of LPI } & The actual value & 3514.320 & 3936.390 & 4405.750 & 4914.660 & 5396.460 \\
\hline & The analog value & 3493.110 & 3466.610 & 4230.980 & 4483.920 & 5127.190 \\
\hline & The error & $1 \%$ & $12 \%$ & $4 \%$ & $9 \%$ & $5 \%$ \\
\hline \multirow{3}{*}{ The output value of MPI } & The actual value & 2728.088 & 2964.237 & 3145.560 & 3329.790 & 3479.644 \\
\hline & The analog value & 2751.730 & 2728.700 & 3087.540 & 3214.290 & 3430.830 \\
\hline & The error & $1 \%$ & $8 \%$ & $2 \%$ & $3 \%$ & $1 \%$ \\
\hline \multirow{3}{*}{ The output value of HPI } & The actual value & 66.472 & 77.073 & 102.880 & 105.180 & 67.956 \\
\hline & The analog value & 69.479 & 67.276 & 97.367 & 98.190 & 62.699 \\
\hline & The error & $5 \%$ & $13 \%$ & $5 \%$ & $7 \%$ & $8 \%$ \\
\hline \multirow{3}{*}{ The energy consumption of LPI } & The actual value & 67.150 & 80.240 & 87.750 & 86.140 & 86.100 \\
\hline & The analog value & 68.849 & 68.498 & 78.327 & 81.449 & 89.139 \\
\hline & The error & $3 \%$ & $15 \%$ & $11 \%$ & $5 \%$ & $4 \%$ \\
\hline \multirow{3}{*}{ The energy consumption of MPI } & The actual value & 2857.234 & 2771.089 & 3090.041 & 2953.295 & 2784.054 \\
\hline & The analog value & 2645.430 & 2628.570 & 2887.700 & 2977.470 & 3128.930 \\
\hline & The error & $7 \%$ & $5 \%$ & $7 \%$ & $1 \%$ & $12 \%$ \\
\hline \multirow{3}{*}{ The energy consumption of HPI } & The actual value & 848.994 & 855.282 & 860.167 & 806.164 & 745.919 \\
\hline & The analog value & 734.742 & 727.532 & 814.670 & 816.771 & 712.015 \\
\hline & The error & $13 \%$ & $15 \%$ & $5 \%$ & $1 \%$ & $5 \%$ \\
\hline \multirow{3}{*}{ Total energy consumption } & The actual value & 3856.022 & 3793.791 & 4132.967 & 3943.954 & 3720.993 \\
\hline & The analog value & 3522.840 & 3502.550 & 3865.520 & 3963.700 & 4024.360 \\
\hline & The error & $9 \%$ & $8 \%$ & $6 \%$ & $1 \%$ & $8 \%$ \\
\hline
\end{tabular}

Table 10. System simulation schemes.

\begin{tabular}{|c|c|c|c|}
\hline Regulatory factor & SP\&WLC & MP\&MLC & WP\&SLC \\
\hline Regulatory factor of investment proportion & $\operatorname{target~} 0.75$ & $\operatorname{target~} 0.65$ & target 0.5 \\
\hline Regulatory factor of GI & -0.008 & 0 & 0.01 \\
\hline Regulatory factor of LPI & -0.06 & 0 & 0.04 \\
\hline Regulatory factor of MPI & 0.05 & 0 & -0.05 \\
\hline Regulatory factor of HPI & 0.018 & target 5 & target 2 \\
\hline Foreign population policy & target 8 & 0 & -0.005 \\
\hline Household population policy & 0.003 & 0 & -0.005 \\
\hline Low-carbon life factor & 0 & -1 & -3 \\
\hline Policy constraints & 1 & & -2 \\
\hline
\end{tabular}




\section{Scenario Analysis}

System dynamics represent a simulation model that can be used to predict the development trend of key variables and to observe the system behavior changes and influences by adjusting for the sensitive variables. We can analyze the trajectory and direction of change to establish a scientific countermeasure. The selected adjustment variables are shown in Table 3. Different combinations of variables constitute three different

a) Total fixed asset investment

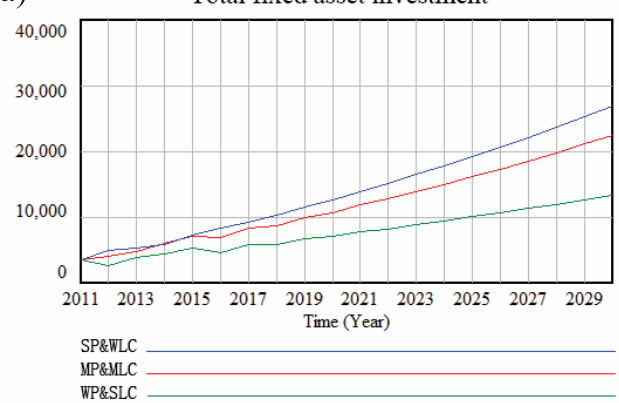

c)

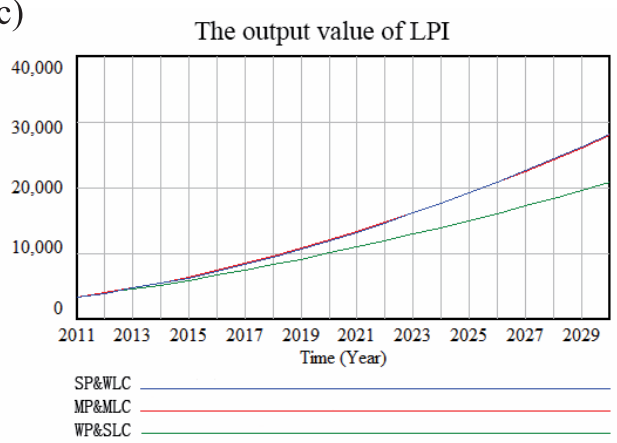

e)

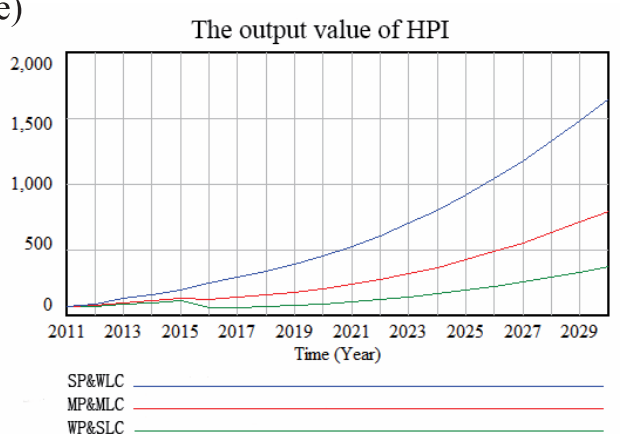

g)

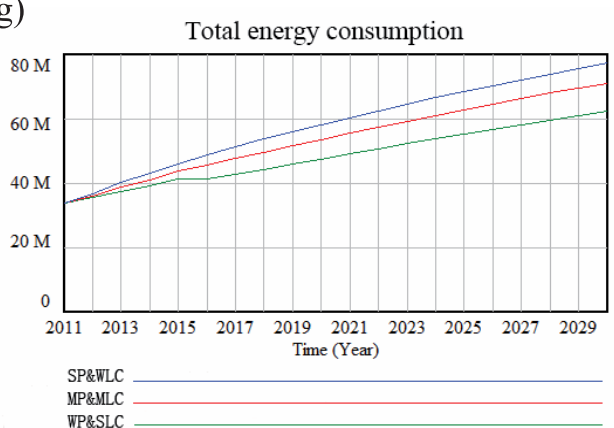

schemes: 1) strong production and weak low-carbon (SP\&WLC); 2) moderate production and moderate lowcarbon (MP\&MLC); 3) and weak production and strong low-carbon (WP\&SLC).

As Table 10 shows, the SP\&WLC scheme reported that the ratio of annual fixed assets investment increased by $5-15 \%$, with the goal of $75 \%$ increases within 20 years; the ratio of annual green industry investment decreased by $0.8 \%$; the ratio of annual light pollution industry investment decreased by $6 \%$; the ratio

b)

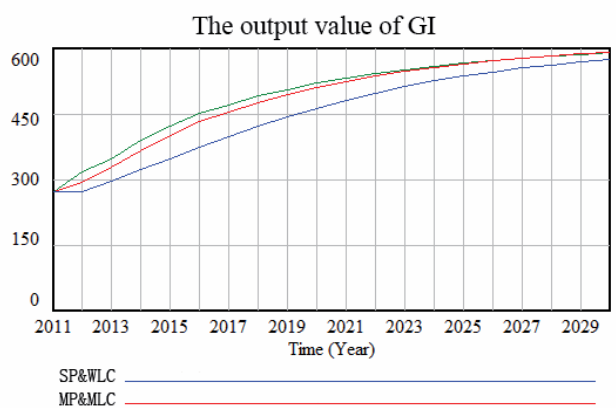

P\&MLC

d)

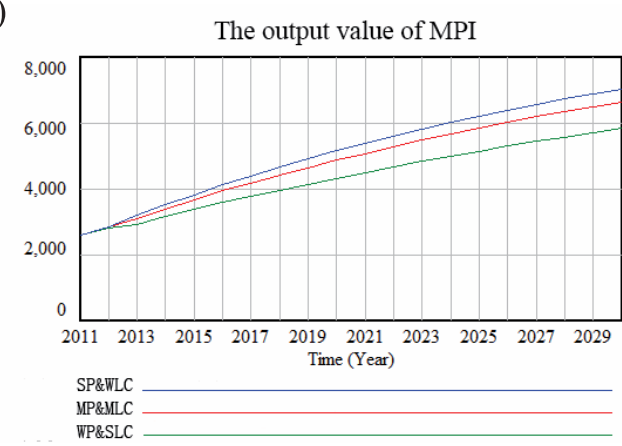

f)

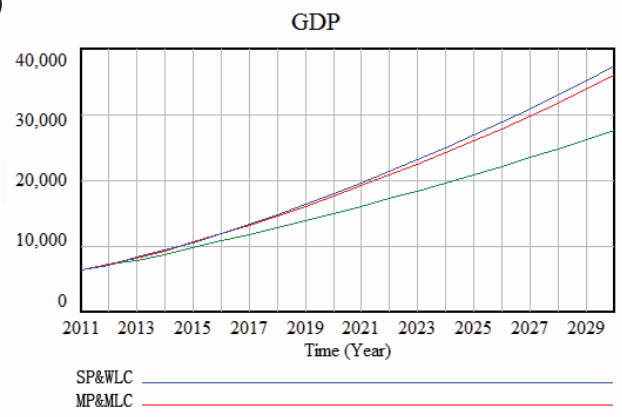

MP\&MLC

h)

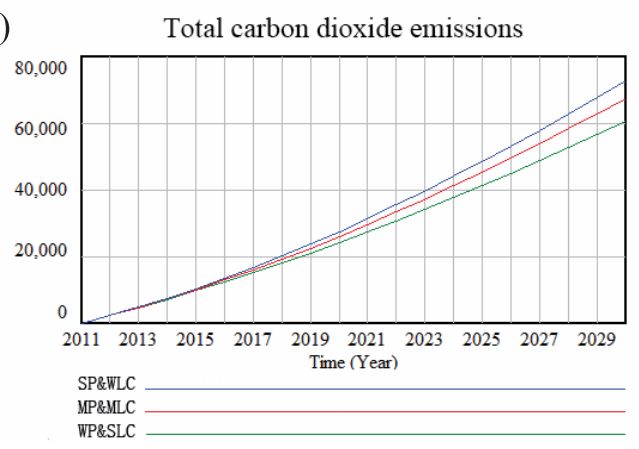

Fig. 4. Operation results under different scenarios. 
of annual moderate pollution industry investment increased by $5 \%$; the ratio of annual heavy pollution industry investment decreased by $1.8 \%$; foreign populations increased by 10-30,000 people with the goal of an 80,000 increase in people; and the natural growth rate of household populations increased by $0.3 \%$ per year. Low-carbon life factor is 0 , and policy constraints on heavy pollution industry is 1 , demonstrating support for production.

The meaning of MP\&MLC and WP\&SLC can be similarly explained.

After adjusting for the sensitive variables, a model was generated to get results under the different scenarios (Fig. 4).

As shown in Figs 4 and 5, the industrial structure of the three different scenarios has been relatively stable over the past five years, and will be relatively stable over the next 15 years. LPI and the MPI account for roughly $95 \%$ of the total output value.
In the SP\&WLC scenario, the proportion of GI output has fallen from $4 \%$ to $2 \%$ within 20 years; the proportion of LPI has increased from $53 \%$ to $75 \%$; the proportion of MPI has fallen from $42 \%$ to $19 \%$; and the proportion of HPI has increased from $1 \%$ to $4 \%$.

In the MP\&MLC scenario, the proportion of GI output has fallen from $4 \%$ to $2 \%$ within 20 years; the proportion of LPI has increased from $53 \%$ to $78 \%$; the proportion of MPI has fallen from $42 \%$ to $21 \%$; and the proportion of HPI has increased from $1 \%$ to $2 \%$.

In the WP\&SLC scenario, the proportion of GI output has fallen from $4 \%$ to $2 \%$ within 20 years; the proportion of LPI has increased from $53 \%$ to $75 \%$; the proportion of MPI has fallen from $42 \%$ to $21 \%$; and the proportion of HPI maintained was approximately $1 \%$.

From the above analysis, the trend of industrial structure adjustment is shown to be consistent and the degree of change is shown to be somewhat different. The proportion of GI and MPI illustrates a downward

a)

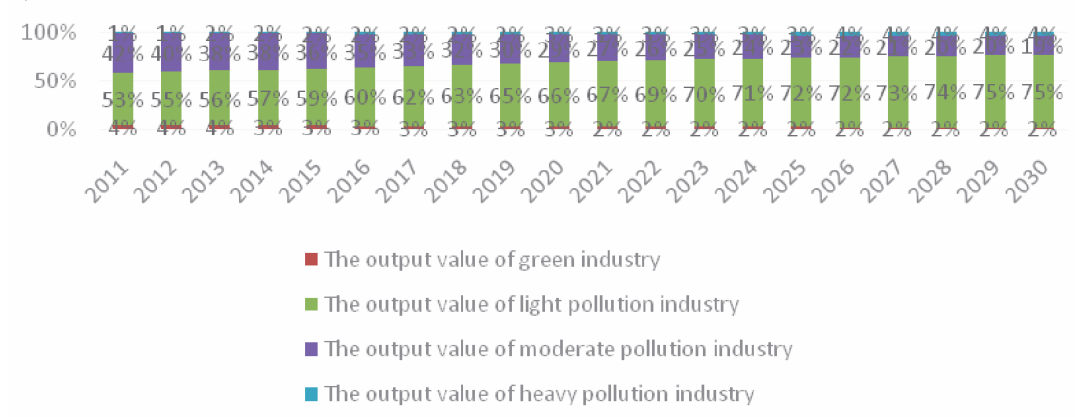

b) Industrial structure of MP\&MLC

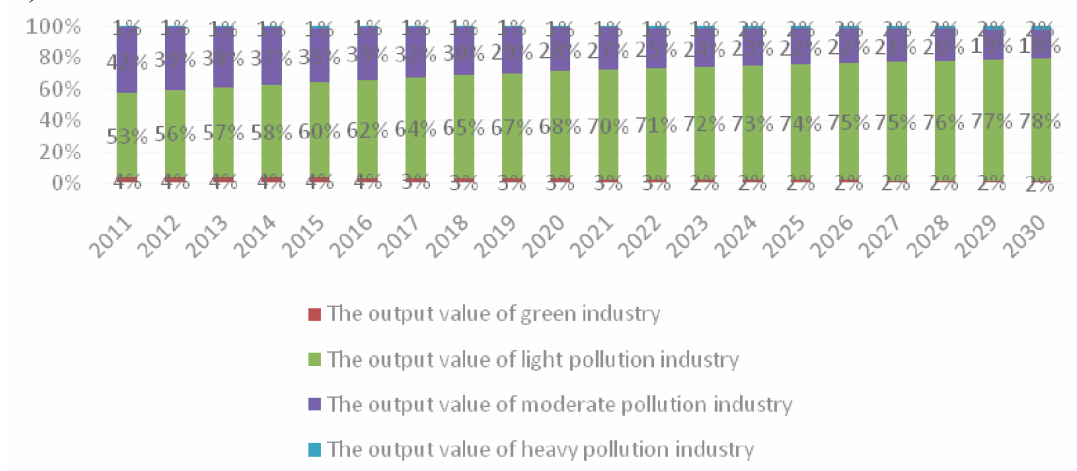

c) Industrial structure of WP\&SLC

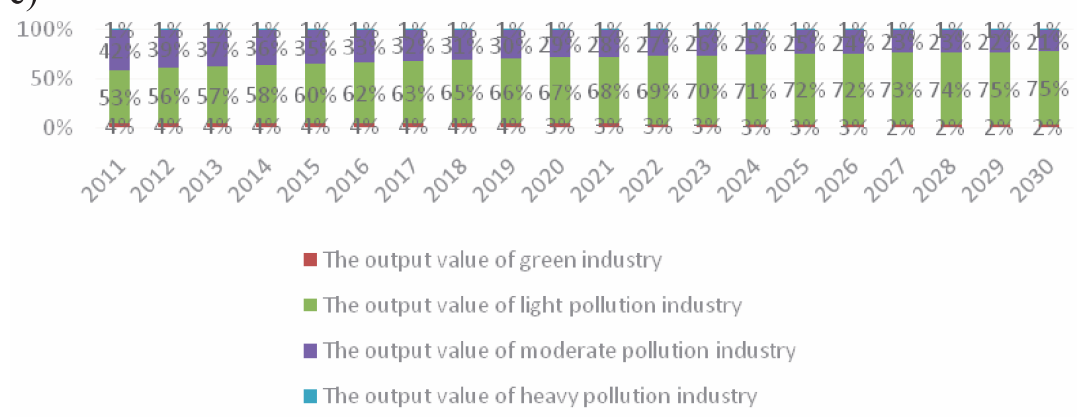

Fig. 5. Comparison of industrial structures in different scenarios. 
trend, but the proportion of LPI and HPI demonstrates an upward trend. Under the three schemes, the industrial structure reached 2:75:19:4, 2:78:18:2 and 2:75:21:1, respectively.

\section{Conclusions}

The coordinated development of the economy and environment of developed eastern coastal region of China is critical to green development, representing one of the core steps of the "green plus" strategy. In examining Qingdao, this paper employs the system dynamics model to simulate the adjustment of industrial structure. We found that the industrial structure plays an important role in coordinating the development of the economy and environment. In addition, the simulation analysis of a variety of scenarios shows that the best coordinated development model of economy and environment is the MP\&MLC model. Conclusions are described as follows:

1. It is reasonable, scientific and feasible to use the system dynamics model to analyze the complex impact mechanism of industrial structure on economic growth and environmental pollution. According to the validity test, the model can effectively reflect the influence of industrial structure on economic and environmental development.

2. Compared to the industrial structure system between 2000 and 2010, the current system of industrial structure in Qingdao has improved; however, there remains a big gap compared to cities in western, developed countries. The Chinese government and the market need to accelerate the pace of industrial restructuring, change the mode of economic growth, and accelerate the realization of intensive economic development models. According to the law of system development, the parameters of the system are adjusted appropriately to simulate the development trend of the industrial structure over the next 15 years. The results show the proportion of light pollution industry, which mainly includes tertiary industry, reaching a reasonable level (approximately 75\%) in the three scenarios. The ratio of heavy pollution industry MP\&MLC and WP\&SLC remains within $3 \%$, and that of SP\&WLC is roughly 4\%. Therefore, MP\&MLC and WP\&SLC are reasonable development scenarios.

3. In terms of economic growth, all three scenarios meet the $12^{\text {th }}$ Five-Year Plan and maintain the city's annual GDP growth of $11 \%$. The economic growth rate of SP\&WLC is close to MP\&MLC's, which is about $2.1 \%$ higher than that of WP\&SLC. All three scenarios meet the the $13^{\text {th }}$ Five-Year Plan and maintain the city's annual GDP growth of $9.7 \%$. The economic growth rate of SP\&WLC is close to MP\&MLC, at $8.9 \%$, but the rate of WP\&SLC is slightly lower than the requirements of the $13^{\text {th }}$ Five-Year Plan. In addition, during the $14^{\text {th }} 15^{\text {th }}$ five-year plan periods, the SP\&WLC and MP\&MLC showed strong economic growth. During the $14^{\text {th }}$ FiveYear Plan period, the average annual growth rate was $8.4 \%$ and $8.1 \%$, respectively, and during the "fifth five" period was $6.8 \%$ and $6.7 \%$, respectively. However, in the WP\&SLC the average annual growth rate only reaches $6.8 \%$ and $5.7 \%$. During the $14^{\text {th }}$ and $15^{\text {th }}$ plan periods, the lack of economic development is a driving force. The WP\&SLC, in contributing to the decline of economic growth, conflicts with the "new normal" economic growth in Qingdao. Therefore, the SP\&WLC and MP\&MLC represent the most appropriate developm

4. In terms of low-carbon development, total SP\&WLC carbon dioxide emissions will be 676.097 million tons by the end of 2029; total MP\&MLC carbon dioxide emissions will be 627.892 million tons; the total WP\&SLC carbon dioxide emissions will be 565.423 million tons. There is a big gap in carbon emissions among the three models. To coordinate environmental and other development, the government should make reasonable choices based on the three scenarios.

5. SP\&WLC makes significant contributes to economic growth while simultaneously creating great pressures on the environment, thus not meeting Qingdao's development goals. WP\&SLC significantly contributes to improving the environment and will reduce nearly 100 million tons of carbon emissions, compared to the SP\&WLC, meeting the economic development goals of the $11^{\text {th }}$ and $12^{\text {th }}$ five-year plans. However, economic development driving force is weak during the $11^{\text {th }}$ Five-Year Plan period, and fails to contribute to future economic development. Compared with the two above-mentioned programs, the economic growth rate of MP\&MLC is close to that of SP\&WLC, and MP\&MLC's carbon emissions are lower than for SP\&WLC. MP\&MLC maintains the rapid development of the economy and also improves the environment. The MP\&MLC model should be pursued in order to maintain high-speed economic growth, smoothly transition into the "new normal" economic development, accelerate formation of the service industry-based industrial structure, and improve the environment.

Altogether, our study shows that improving the environment and speeding-up economic restructuring represent gradual, long-term projects. However, there are some limitations to our analysis. Our classification of pollution levels is based on carbon emissions, and the analysis of the pollution level and impact of other pollutants are not sufficient. To support addressing the actual needs of different regions, future research should be conducted on various types of pollutants.

\section{Acknowledgements}

This project was supported by the National Social Science Fund of China (15BJY070). 


\section{Conflict of Interest}

The authors declare no conflict of interest.

\section{References}

1. ZHANG B., YU S. A Quantitative Analysis of the Index System of Qingdao 's Economic Development. Journal of the Party School of C.P.C. Qingdao Municipal Committee and Qingdao Administrative Institue, 4, 120, 2010.

2. PAUL S., BHATTACHARYA R.N. $\mathrm{CO}_{2}$ emission from energy use in India: a decomposition analysis. Energy Policy, 32 (5), 585, 2004.

3. IPEK TUNC G., TÜRÜT-ASIK S., AKBOSTANCI E. A decomposition analysis of $\mathrm{CO}_{2}$ emissions from energy use: Turkish case. Energy Policy, 37 (11), 4689, 2009.

4. ZHU Q., PENG X., FU X. Simulated Analysis of Population Development and Carbon Emission in Future China. Population and Development, 1, 2, 2011.

5. PANG J., JIAO J., LI L. Analysis of household carbon emissions in China by system dynamics. Journal of Hefei University of Technology (Natural Science), 2, 260, 2017.

6. ZHANG J., LEI H., LI J. Research on Building Urban Low-carbon Transportation System Based on System Dynamics. Soft Science, 4, 77, 2012.

7. ZHOU Y. The Studies on Urban Transportation Energy Consumption and Carbon Emissions Based on the View of System Dynamics: Take Hangzhou as the Example. Urban Development Studies, 9, 99, 2012.

8. ASAFU-ADJAYE J., MAHADEVAN R. Implications of $\mathrm{CO}_{2}$ reduction policies for a high carbon emitting economy. Energy Economics, 38, 32, 2013.

9. DURO J.A., PADILLA E. International inequalities in per capita $\mathrm{CO}_{2}$ emissions: A decomposition methodology by Kaya factors. Energy Economics, 28 (2), 170, 2006.
10. BASTOLA U., SAPKOTA P. Relationships among energy consumption, pollution emission, and economic growth in Nepal. Energy, 80, 254, 2015.

11. FAN T. Research on Development Pattern of Low-carbon Economy Based on System Dynamics Model: A Case of Fujian. East China Economic Management, 27 (7), 12, 2013.

12. STIROH K.J., JORGENSON D.W. U.S. Economic Growth at the Industry Level. American Economic Review, 90 (2), 161, 2000. Retrieved from https://ideas.repec.org/a/aea/ aecrev/v90y2000i2p161-167.html

13. MINIHAN E.S., WU Z. Economic structure and strategies for greenhouse gas mitigation. Energy Economics, 34 (1), $350,2012$.

14. XU T. Study of Relationship in Economic Growth, Environmental Quality and Industrial Structure in Shaanxi. On Economic Problems, 4, 48, 2011.

15. YUAN Y., XIE R. Research on the Effect of Environment Regulation to Industrial Restructuring - Empirical Test Based on Provincial Panel Data of China. China Industrial Economics, 8, 57, 2014.

16. PARK S., LEE S., JEONG S.J., SONG H.-J., PARK J.-W. Assessment of $\mathrm{CO}_{2}$ emissions and its reduction potential in the Korean petroleum refining industry using energyenvironment models. Energy, 35 (6), 2419, 2010.

17. ASLANI A., HELO P., NAARANOJA M. Role of renewable energy policies in energy dependency in Finland: System dynamics approach. Applied Energy, 113, 758, 2014.

18. HAN N. Simulation and Prediction on the Effect of Industrial Structure Adjustment to Environmental Pollution in China Based on System Dynamics. Forum on Science and Technology in China, 10, 53, 2016.

19. XU S., WU D. Analysis on the 'industry-economyresources' simulated system of Poyang Lake Eco-industrial Clusters based on systematic dynamics. Resources Science, 5, 871, 2016. 